\title{
Olfactory Signal Transduction in the Mouse Septal Organ
}

\author{
Minghong Ma, ${ }^{1}$ Xavier Grosmaitre, ${ }^{1}$ Carrie L. Iwema, ${ }^{2}$ Harriet Baker, ${ }^{3}$ Charles A. Greer,,${ }^{1,2}$ and Gordon M. Shepherd ${ }^{1}$ \\ Departments of ${ }^{1}$ Neurobiology and ${ }^{2}$ Neurosurgery, Yale Medical School, New Haven, Connecticut 06520, and ${ }^{3}$ Weill Medical College, Cornell University, \\ White Plains, New York 10605
}

\begin{abstract}
The septal organ, a distinct chemosensory organ observed in the mammalian nose, is essentially a small island of olfactory neuroepithelium located bilaterally at the ventral base of the nasal septum. Virtually nothing is known about its physiological properties and function. To understand the nature of the sensory neurons in this area, we studied the mechanisms underlying olfactory signal transduction in these neurons. The majority of the sensory neurons in the septal organ express olfactory-specific G-protein and adenylyl cyclase type III, suggesting that the cAMP signaling pathway plays a critical role in the septal organ as in the main olfactory epithelium (MOE). This is further supported by patch-clamp recordings from individual dendritic knobs of the sensory neurons in the septal organ. Odorant responses can be mimicked by an adenylyl cyclase activator and a phosphodiesterase inhibitor, and these responses can be blocked by an adenylyl cyclase inhibitor. There is a small subset of cells in the septal organ expressing a cGMP-stimulated phosphodiesterase (phosphodiesterase 2), a marker for the guanylyl cyclase-D subtype sensory neurons identified in the MOE. The results indicate that the septal organ resembles the $\mathrm{MOE}$ in major olfactory signal transduction pathways, odorant response properties, and projection to the main olfactory bulb. Molecular and functional analysis of the septal organ, which constitutes $\sim 1 \%$ of the olfactory epithelium, will provide new insights into the organization of the mammalian olfactory system and the unique function this enigmatic organ may serve.
\end{abstract}

Key words: septal organ; main olfactory epithelium; signal transduction; cAMP pathway; adenylyl cyclase III; $\mathrm{G}_{\text {olf }}$; guanylyl cyclase-D; phosphodiesterase 2; olfactory sensory neuron

\section{Introduction}

It has become clear recently that the mammalian olfactory system consists of several subsystems, each of which may serve distinct functions by using different signal transduction pathways and projecting to different brain areas (for review, see Zufall and Munger, 2001). One of the subsystems is the septal organ (SO) (organ of Masera), a chemosensory organ in the mammalian nasal cavity first systematically described by Rodolfo-Masera (1943). It is essentially a small island of olfactory epithelium lying near the ventral base of the nasal septum at the entrance to the nasopharynx. It is separated from the main olfactory epithelium (MOE) by surrounding respiratory epithelium (RE). Although the septal organ has been observed in many mammals (Adams and McFarland, 1971; Bojsen-Moller, 1975; Katz and Merzel, 1977; Kratzing, 1984; Breipohl et al., 1983, 1989; Taniguchi et al., 1993), virtually nothing is known about the properties of the olfactory sensory neurons (OSNs) in this area. To attack this problem, we first investigated signal transduction mechanisms in these neurons compared with the MOE.

The majority of the ciliated OSNs in the MOE use the cAMP signaling cascade for transforming chemosensory information

\footnotetext{
Received Aug. 16, 2002; revised 0ct. 18, 2002; accepted 0ct. 22, 2002.

This work was supported by the following: National Institute on Deafness and Other Communication Disorders (NIDCD)/National Institutes of Health (NIH) Grant DC05127 and the Whitehall Foundation (M.M.); National Institute on Aging (NIA)/NIH Grant AG09686 (H.B.); NIDCD Grants DC00210 and DC03887 (C.A.G.); NIDCD Grant DC00086 (G.M.S.); NIDCD, NIA, NASA, and National Institute of Mental Health (Human Brain Project) (G.M.S.); and the Army Research Office (Multidiciplinary University Research Initiative) (G.M.S.). We thank Drs. Helen Treloar, Brian Lipscomb, and Wei Chen for their insightful discussions.

Correspondence should be addressed to Dr. Minghong Ma's present address: Department of Neuroscience, University of Pennsylvania, 215 Stemmler Hall, 3450 Hamilton Walk, Philadelphia, PA 19104. E-mail: mma@mail.med.upenn.edu.

Copyright $\odot 2002$ Society for Neuroscience $\quad 0270-6474 / 02 / 220317-08 \$ 15.00 / 0$
}

into electrical signals. Such a cascade involves sequential activation of olfactory-specific G-protein $\left(G_{\text {olf }}\right)$, adenylyl cyclase type III (ACIII), and cyclic nucleotide-gated (CNG) channel. This is supported by evidence from biochemistry (Pace et al., 1985; Sklar et al., 1986; Breer et al., 1990), physiology (Chen et al., 2000; Spehr et al., 2002), immunohistochemistry, in situ hybridization (Jones and Reed, 1989; Bakalyar and Reed, 1990; Berghard et al., 1996), and gene knock-out (Brunet et al., 1996; Belluscio et al., 1998; Wong et al., 2000). Recently, 3-phosphoinositide has been shown to modulate the cAMP signaling in rodent OSNs (Spehr et al., 2002).

A small subset of the OSNs in the MOE has been found to define a distinct signal transduction pathway. Instead of expressing the key components in the cAMP pathway, these neurons coexpress guanylyl cyclase-D (GC-D) (Fulle et al., 1995), a cGMP-stimulated phosphodiesterase [phosphodiesterase 2 (PDE)] (Juilfs et al., 1997), and a cGMP-sensitive CNG channel (Meyer et al., 2000). These neurons project to the necklace glomeruli (Juilfs et al., 1997; Baker et al., 1999), which may be involved in suckling behavior (Teicher et al., 1980; Greer et al., 1982; Yagi et al., 1993).

We evaluated the contribution of these two distinct pathways identified in the MOE to olfactory signal transduction in the septal organ. The results indicate that cAMP mediates olfactory signal transduction in most OSNs in the septal organ. The septal organ resembles the MOE in odorant response properties and projection to the main olfactory bulb. Because the septal organ presents a much smaller, potentially simpler system than the MOE, functional and molecular characterization of the OSNs in this area will provide critical information about olfactory coding and processing in general and shed light on its behavioral significance. 


\section{Materials and Methods}

Immunohistochemistry. Male or female C57BL/6 mice at the age of $7 \mathrm{~d}$ to 12 weeks were used. After deep anesthesia with an intraperitoneal injection of ketamine $\mathrm{HCl}(300 \mathrm{mg} / \mathrm{kg}$ body weight), the animal was transcardially perfused with PBS (0.1 M phosphate buffer and $0.9 \% \mathrm{NaCl}, \mathrm{pH} 7.4)$ and fixed by perfusion with $4 \%$ paraformaldehyde in $0.1 \mathrm{M}$ PBS for $5 \mathrm{~min}$. The nose was dissected out en bloc and further fixed in 4\% paraformaldehyde for $2 \mathrm{hr}$ at room temperature. For whole-mount olfactory epithelium staining, the olfactory epithelia attached to the septum were used. For preparation of sections, the nose was decalcified overnight in $0.2 \mathrm{M}$ EDTA and infiltrated with $30 \%$ sucrose before embedded in OCT (Tissue-Tek, Miles Laboratories, Elkhart, IN) and sectioned at 15-20 $\mu \mathrm{m}$ on a cryostat. Tissues were first blocked for $30 \mathrm{~min}$ with $2 \%$ bovine serum albumin and $0.3 \%$ Triton X-100 in TBS ( $0.1 \mathrm{M}$ Tris buffer and $0.9 \% \mathrm{NaCl}$, $\mathrm{pH} 7.4$ ) and then incubated with the primary antisera in $0.1 \mathrm{M}$ TBS with $0.3 \%$ Triton X-100 for $2 \mathrm{hr}$ at room temperature. The primary antisera include rabbit anti- $\alpha$ subunit of $\mathrm{G}_{\text {olf }}$ (1:400; Santa Cruz Biotechnology, Santa Cruz, CA), rabbit anti-ACIII (1:400; Santa Cruz Biotechnology), goat anti-olfactory marker protein (OMP) (1:1000; kindly provided by Dr. F. Margolis, University of Maryland, Baltimore, MD), and mouse monoclonal anti-growth associated protein-43 (GAP-43) (1:1000; Sigma, St. Louis, MO). Immunofluorescence was achieved by reaction with appropriate secondary antibodies at 1:200 for $1 \mathrm{hr}$. The secondary antibodies include donkey anti-rabbit-RRX, donkey anti-goat-Cy2, donkey anti-mouse-488, and donkey anti-goat-568 (Jackson ImmunoResearch, West Grove, PA). Tissues were washed in $0.1 \mathrm{~m}$ TBS and mounted in Vectashield (Vector Laboratories, Burlingame, CA). Pictures were taken under a Bio-Rad (Hercules, CA) 600 scanning confocal microscope. For PDE2 labeling, whole-mount epithelia were incubated in the primary antisera for $3 \mathrm{~d}$ at $4^{\circ} \mathrm{C}(1: 50$; kindly provided by Dr. J. Beavo, University of Washington, Seattle, WA), followed by an overnight incubation in biotinylated donkey anti-chicken secondary antiserum and normal mouse serum (Jackson ImmunoResearch). Positive staining was detected with the ABC kit (Vector Laboratories) using DAB (Sigma) as the chromogen.

DiI tracing. After transcardiac perfusion with $4 \%$ paraformaldehyde, the head was further fixed overnight at $4^{\circ} \mathrm{C}$. The nasal cavities were opened up to expose the septum. The main olfactory epithelium was covered up before DiI crystals (Molecular Probes, Eugene, OR) were placed in the septal organ area. The labeling patterns in the epithelium and in the olfactory bulb were examined after 6 weeks. The olfactory bulbs were cut into $50 \mu \mathrm{m}$ sections, which were examined under an upright infrared differential interference contrast (DIC) microscope (Olympus BX50WI; Olympus Optical, Tokyo, Japan) equipped with fluorescence attachment. Because the OSNs in the septal organ form only one or two fascicles when they project to the olfactory bulb, the experiments with any labeling in the main olfactory epithelium were discarded.

Electrophysiology. The intact epithelial preparations were prepared following previously published procedures (Ma et al., 1999; Ma and Shepherd, 2000). Mice (4-12 weeks) were deeply anesthetized by injection of ketamine and decapitated. The head was immediately put into icy Ringer's solution, which contained the following (in $\mathrm{mm}$ ): $124 \mathrm{NaCl}, 3 \mathrm{KCl}$, $1.3 \mathrm{MgSO}_{4}, 2 \mathrm{CaCl}_{2}, 26 \mathrm{NaHCO}_{3}, 1.25 \mathrm{NaH}_{2} \mathrm{PO}_{4}$, and 15 glucose $15, \mathrm{pH}$ 7.6 (305 mOsm). The nose was dissected out en bloc, and the olfactory epithelium attached to the nasal septum was removed and kept in oxygenated Ringer's solution. Before use, the whole epithelium attached to the septum was peeled off and transferred to a recording chamber with the mucus layer facing up, and the oxygenated Ringer's solution was continuously perfused at $25 \pm 2^{\circ} \mathrm{C}$. The dendritic knobs of the OSNs were visualized through an upright infrared DIC microscope (Olympus BX50WI) equipped with a CCD camera (Dage-MTI, Michigan City, IN) and a $40 \times$ objective. Perforated patch clamp was performed on the dendritic knobs by including $260 \mu \mathrm{M}$ amphotericin B in the recording pipette, which was filled with the following solution (in $\mathrm{mm}$ ): $17.7 \mathrm{KCl}$, 105.3 KOH, 82.3 methanesulfonic acid, 5.0 EGTA, 10 HEPES, and 70 sucrose, pH $7.2(\mathrm{KOH} ; 310 \mathrm{mOsm})$. Electrophysiological recordings were controlled by an EPC-9 amplifier combined with the Pulse/Pulsefit software (Heka Electronik, Lambrecht/Pfalz, Germany). A multibarrel

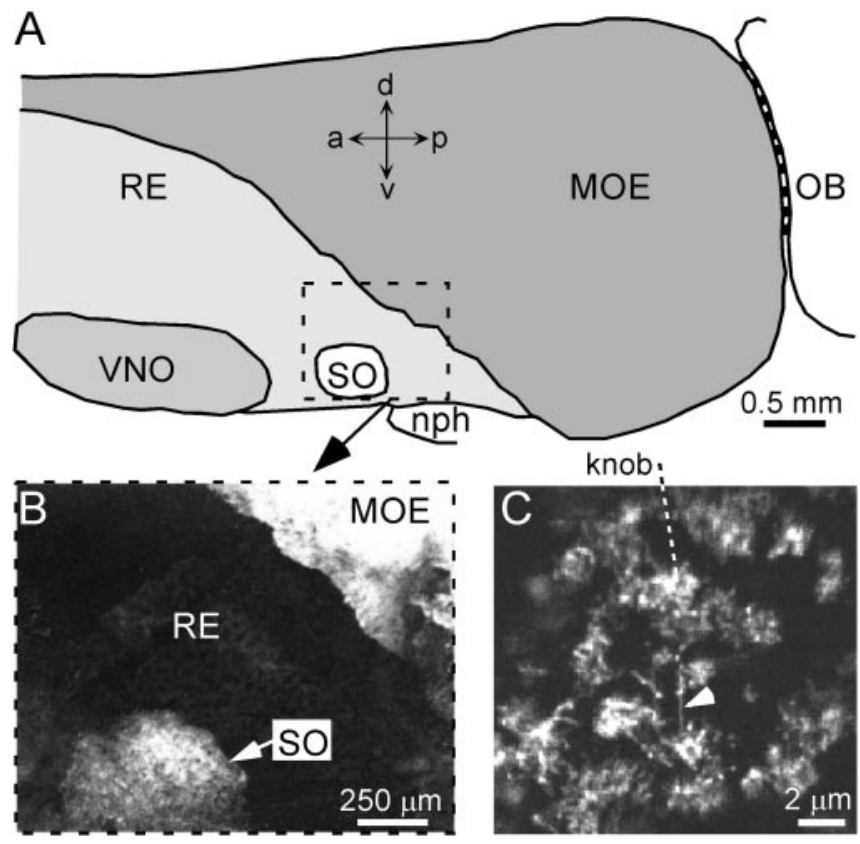

Figure 1. The septal organ in the whole-mount epithelium preparation was identified by labeling with the ACIII antibody. $A$, The contour of the epithelium attached to the septum was drawn according to a 6 -week-old female mouse. The septal organ is a small island of olfactory epithelium surrounded by respiratory epithelium lying near the base of the nasal septum at the entrance to the nasopharynx. $M O E$, Main olfactory epithelium; $S O$, septal organ; $R E$, respiratory epithelium; VNO, vomeronasal organ; $n p h$, nasopharynx; $O B$, olfactory bulb; $a$, anterior; $p$, posterior; $d$, dorsal; $v$, ventral. $B$, The area within the dotted rectangle in $A$ viewed under fluorescence illumination. Both the MOE and the SO, but not the RE, were labeled with the ACIII antibody. C, The ACIII-stained dendritic knobs and cilia (arrow) of the sensory neurons in the septal organ visualized under higher magnification.

pipette, placed $\sim 10 \mu \mathrm{m}$ downstream from the recording site, was used to deliver stimuli by pressure ejection through a Picospritzer (General Valve, Fairfield, NJ). All odorants were prepared as a $0.5 \mathrm{M}$ stock solution in dimethylsulfoxide (DMSO) and diluted to the final concentrations by adding Ringer's solution. The odorant mixture contained equal concentration of the following 20 compounds from various classes: acetophenone, amyl acetate, anisaldehyde, benzyldehyde, (+)carvone, $(-)$ carvone, cineole, ethyl vanilline, heptanal, heptanoic acid, 2-heptanone, 3-heptanone, heptanol, hexanal, (+)limonene, (-)limonene, lyral, octanal, octanoic acid, and octanol. 3-Isobutyl-1-methyl-xanthine (IBMX) was prepared in a $20 \mathrm{~mm}$ stock solution containing $5 \%$ DMSO and diluted to the final concentrations before use. Forskolin, IBMX, 8-bromoguanosine-3', $5^{\prime}$-cyclomonophosphate (8-Br-cGMP), and MDL12330A were purchased from Sigma.

\section{Results}

cAMP signaling in the septal organ: immunohistochemical evidence

To identify the signal transduction pathways in the septal organ, we started with the role of cAMP because it has been established as the second messenger underlying signal transduction in the MOE. We compared the immunohistochemical staining patterns of antibodies against ACIII and the $\alpha$ subunit of $\mathrm{G}_{\text {olf }}$, two key elements in the cAMP pathway. Figure 1 shows the staining pattern of ACIII antibody in a whole-mount epithelium attached to the nasal septum, which clearly defined the position of the septal organ. Both the septal organ and the MOE were stained with the ACIII antibody (Fig. 1 $A, B$ ). The septal organ was a small island of olfactory epithelium located at the ventral base of the septum, posterior to the vomeronasal organ and near the entrance of the nasopharynx. It was separated from the MOE by surrounding RE, 

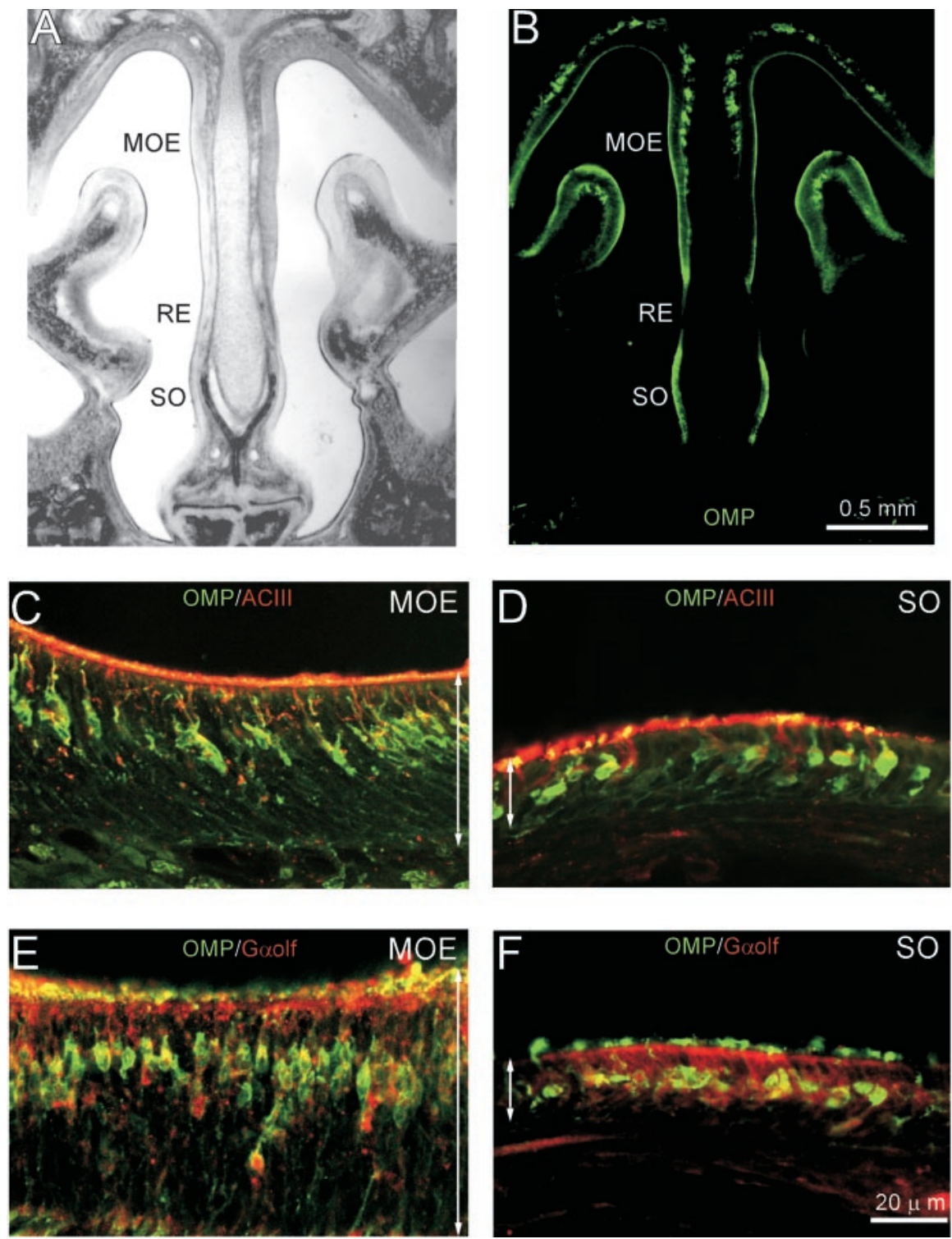

Figure 2. OSNs in the septal organ were labeled with $A C I I I$ and $G_{\text {olf }}$ antibodies. $A, B$, In a coronal section, the $S O$ was distinguished from the MOE by its location as revealed by OMP staining. The same section is shown under transmitted light $(A)$ and fluorescence illumination $(B)$. The $S O$ is separated from the MOE by surrounding respiratory epithelium, which is OMP negative. $C-F$, Both the $\operatorname{MOE}(C, E)$ and the $S O(D, F)$ were labeled with $A C I I I$ and $G_{\text {olf }}$ antibodies, two key components in the CAMP signal transduction pathway. OMP is in red, and $A C I I I(C, D)$ or $G_{\text {olf }}(E, F)$ is in green. The arrows indicate the thickness of the epithelium. The results in this figure and Figure 3 were from 7-d-old animals.

which was ACIII negative. The labeled dendritic knobs and cilia in the septal organ were readily visualized under higher magnification (Fig. 1C).

To compare further the staining patterns in the two systems at the level of individual cells, ACIII and $\mathrm{G}_{\text {olf }}$ labeling patterns were examined in olfactory epithelium sections and double labeled with OMP antibody, which stains mature OSNs (Keller and Margolis, 1975) (Fig. 2). In a coronal section, the septal organ was separated from the MOE by a region of respiratory epithelium, which was OMP negative (Fig. $2 A, B$ ). The ACIII antibody strongly labeled the superficial layer, in which the dendritic knobs and cilia of OSNs were located, in both the MOE and the septal organ (Fig. 2C,D). Other than the superficial layer, the $\mathrm{G}_{\text {olf }}$ antibody also labeled the dendrites and cell bodies in both systems (Fig. 2E,F). The similarity in the staining patterns of ACIII and
$\mathrm{G}_{\text {olf }}$ antibodies suggests that the cAMP pathway may play a similar role in the two systems.

Although the staining patterns of the OMP-ACIII or $G_{\text {olf }}$ were similar in the two systems, there were some differences in cell morphology (Fig. 2C-F). The OSNs in the septal organ appeared to have flattened somata and shorter dendrites than those in the MOE, and there were fewer layers of cells. The thickness of the epithelium was $\sim 20 \mu \mathrm{m}$ compared with $60-80 \mu \mathrm{m}$ in the MOE, depending on the location. This was more clearly shown with double staining using antibodies against OMP and GAP-43, which labels immature OSNs (Fig. $3 A, B$ ). There were three to four layers of both mature and immature neurons in the MOE (Fig. 3A) and one to two layers of each type in the septal organ (Fig. 3B). As a result, the density of the dendritic knobs was lower in the septal organ, which was demonstrated in a whole-mount olfactory epithelium stained with ACIII antibody (Fig. 3C) (see also below).

\section{cAMP signaling in the septal organ: electrophysiological evidence}

To obtain physiological evidence that the cAMP pathway mediates olfactory signal transduction in the septal organ, we performed perforated patch-clamp recordings on the dendritic knobs of individual OSNs in the intact epithelial preparation. In such a preparation, the septal organ can be distinguished from the MOE under DIC microscopy (Fig. 4). The RE was separated from the MOE and the SO by sharp boundaries (Fig. 4A). Under higher magnification, both the MOE and the SO were featured by Bowman's gland openings, supporting cells and dendritic knobs of OSNs, whereas the RE was featured by epithelial cells with moving microvilli (Fig. $4 B)$. The size of the septal organ in 10week-old mice was $0.28 \pm 0.02 \mathrm{~mm}^{2}(n=$ 5 ; mean \pm SE) compared with $7.7 \pm 3.1$ $\mathrm{mm}^{2}(n=5)$ of the MOE attached to the septum. There were $\sim 14,000$ mature OSNs in the septal organ based on an average density of $5 \times 10^{4}$ dendritic knobs $/ \mathrm{mm}^{2}$, which was determined by averaging the number of dendritic knobs in 10 randomly selected areas $(10 \times 10 \mu \mathrm{m})$ in the intact olfactory epithelial preparations from three animals. The dendritic knobs in the septal organ appeared to be bigger than those in the MOE, i.e., the diameters ranged from 2 to $3 \mu \mathrm{m}$ compared with 1 to $2 \mu \mathrm{m}$ in the MOE, which facilitated physiological recordings from individual OSNs in the septal organ.

Odorant-induced responses recorded from the OSNs in the septal organ showed similar properties as those in the MOE. Odorants always induced inward currents in these neurons under voltage-clamp mode (Fig. 5A1). An odorant mixture that contained 20 compounds in various classes (see Materials and Meth- 

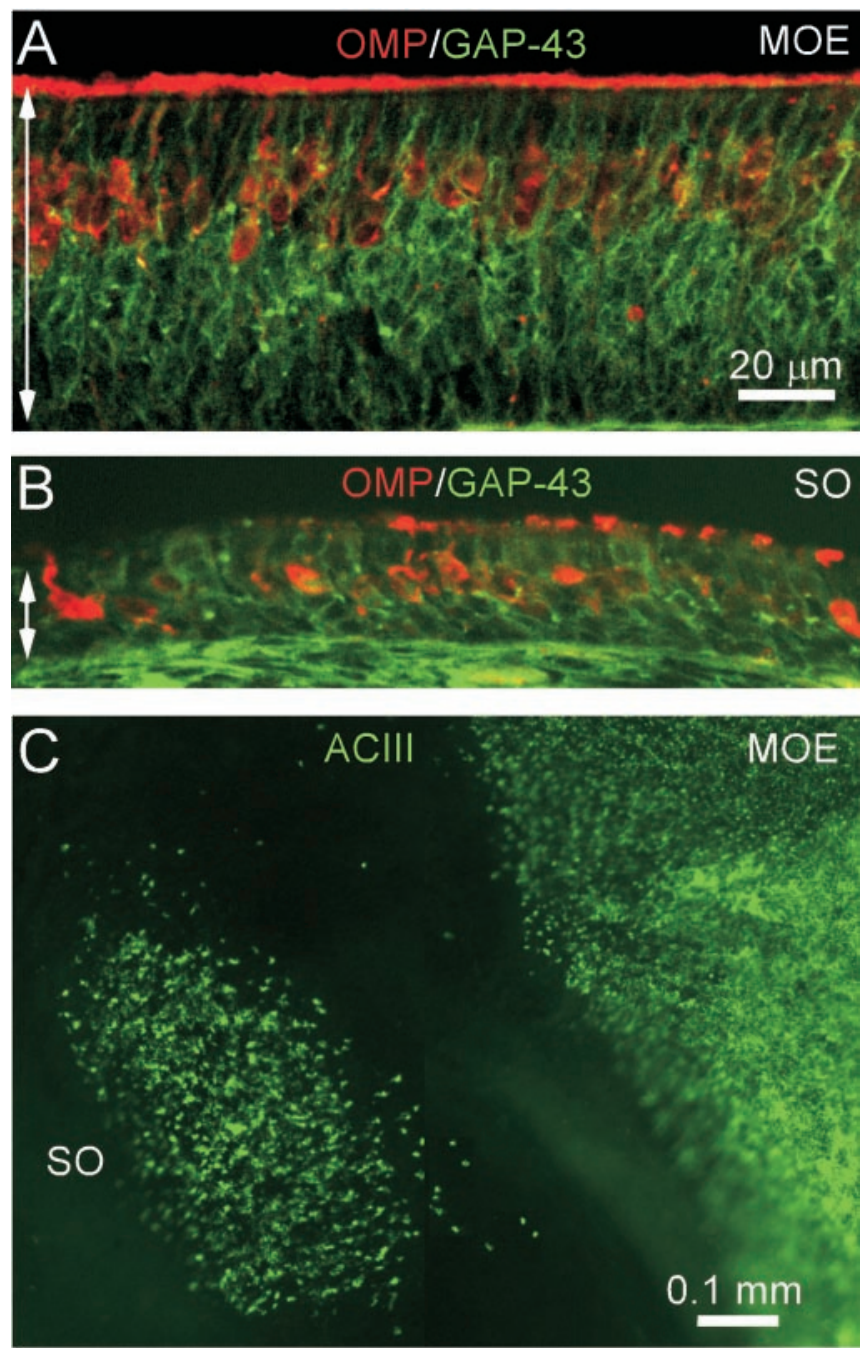

Figure 3. The $S O$ has a lower density of OSNs than the MOE. $A, B$, Sections of the MOE and the SO were compared by double labeling with OMP (red) and GAP-43 ( green) antibodies. There are three to four layers of mature (OMP-positive) and immature (GAP-43-positive) cells in MOE and only one to two layers of each type in $\mathrm{SO}$. The cells in $\mathrm{SO}$ appear to have flattened somata and shorter dendrites. The arrows indicate the thickness of the epithelium. C, Whole-mount epithelium attached to the septum labeled by the ACIII antibody demonstrates a lower density of the dendritic knobs in the $\mathrm{SO}$ than in the MOE.

ods) induced responses in seven of eight cells tested. Three single compounds were also examined in the OSNs in the septal organ. Amyl acetate elicited inward currents in four cells of seven tested, $(+)$ limonene in three of six, and $(-)$ limonene in four of seven. Some cells (three of six in which all three compounds were tested) responded to more than one odorant.

To test whether olfactory signal transduction in the septal organ is mediated by the cAMP signaling cascade, we applied several compounds that can activate or inhibit the key components in this pathway. Forskolin, a potent activator of adenylyl cyclase, mimicked odorant-induced inward currents in these neurons (Fig. 5B1). IBMX has been widely used in vertebrate OSNs to mimic odorant responses, presumably by increasing intracellular cyclic nucleotide levels, which in turn open the CNG channels (Firestein et al., 1991a,b; Lowe and Gold, 1993). Likewise, IBMX also elicited inward currents in the OSNs in the septal organ (Fig. $5 \mathrm{Cl}$ ). Although cAMP serves as the major second messenger mediating olfactory signal transduction in vertebrate OSNs, it has been well established that olfactory CNG channels are sensitive to both cAMP and cGMP (Nakamura and Gold, 1987; Kurahashi, 1990; Firestein et al., 1991a; Zufall et al., 1991). Traditionally, 8-Br-cGMP, a membrane-permeable analog of cGMP, is used as an activator of these channels (Firestein et al., 1991a; Leinders-Zufall et al., 1995; Chen et al., 2000). Similar to other vertebrate OSNs reported in the literature, the neurons in the septal organ also responded to 8 -Br-cGMP by generating inward currents (Fig. 5D1). To elucidate the critical role played by cAMP generated through activation of adenylyl cyclase, we tested the effect of MDL12330A, a blocker of adenylyl cyclase on these responses (Chen et al., 2000; Spehr et al., 2002). MDL12330A at $50 \mu \mathrm{M}$ completely blocked responses induced by odorants, forskolin, and IBMX within 5 min of perfusion (Fig. $5 A-C, E)$. Recovery started to occur within 5 min after wash out (data not shown). Because 8-Br-cGMP activates the CNG channels directly, MDL12330A did not have an effect on 8-Br-cGMPelicited responses (Fig. 5D2,E). These results indicate that the septal organ uses the cAMP pathway as the major signal transduction mechanism.

To investigate further odorant response properties of individual OSNs in the septal organ, we examined olfactory adaptation during repetitive odorant exposures, which has been studied extensively in vertebrate OSNs (for review, see Zufall and LeindersZufall, 2000). One of the key cellular steps involved in such a process is negative modulation of the CNG channels by $\mathrm{Ca}^{2+}$ influx (Kramer and Siegelbaum, 1992; Kurahashi and Menini, 1997), with new evidence pointing to individual subunits of these heteromultimeric channels (Bradley et al., 2001; Munger et al., 2001). When paired odorant pulses were delivered to individual OSNs in the MOE or in the septal organ, the second stimulus typically elicited a smaller response (Fig. $6 A, B$ ), which increased with the prolonged interpulse intervals. Because the recovery from olfactory adaptation showed some variations in different cells tested with different odorants and different concentrations, we compared the time course for recovery from adaptation induced by IBMX stimuli in the two systems (Fig. $6 C, D$ ). Paired IBMX pulses induced adaptation, presumably by increasing the cAMP level mimicking the downstream cellular steps after the cAMP formation, because IBMX responses were blocked by an adenylyl cyclase blocker (Fig. 5C2). A full recovery took 10-12 sec in both the MOE and the septal organ (Fig. 6E). These recordings demonstrate that the OSNs in the septal organ show similar adaptation properties as those in the MOE.

\section{A small subset of OSNs in the septal organ belongs to the GC-D-PDE2 subfamily}

A subset of OSNs in the MOE may define another signal transduction mechanism, which depends on cGMP. Although there is no functional evidence for such a cGMP-mediated transduction cascade, it has been established that that these cells express distinct molecular markers, such as GC-D and PDE2, and project to the necklace glomeruli, which are well described both immunohistochemically and topographically (Zheng et al., 1987; Shinoda et al., 1989; Ring et al., 1997; Weruaga et al., 2001). Injection of horseradish peroxidase (HRP) in the area including the modified glomerular complex, part of the necklace glomeruli, resulted in retrograde-labeled cells in both the MOE and the septal organ in rats (Pedersen and Benson, 1986). This indicates a possibility that the septal organ cells may also be involved in this pathway. To test such a possibility, we compared the immunostaining pattern of a specific marker for GC-D neurons in the MOE and in the septal organ and examined the projection pattern of the septal organ.

Whole-mount epithelial tissues were labeled with PDE2 anti- 


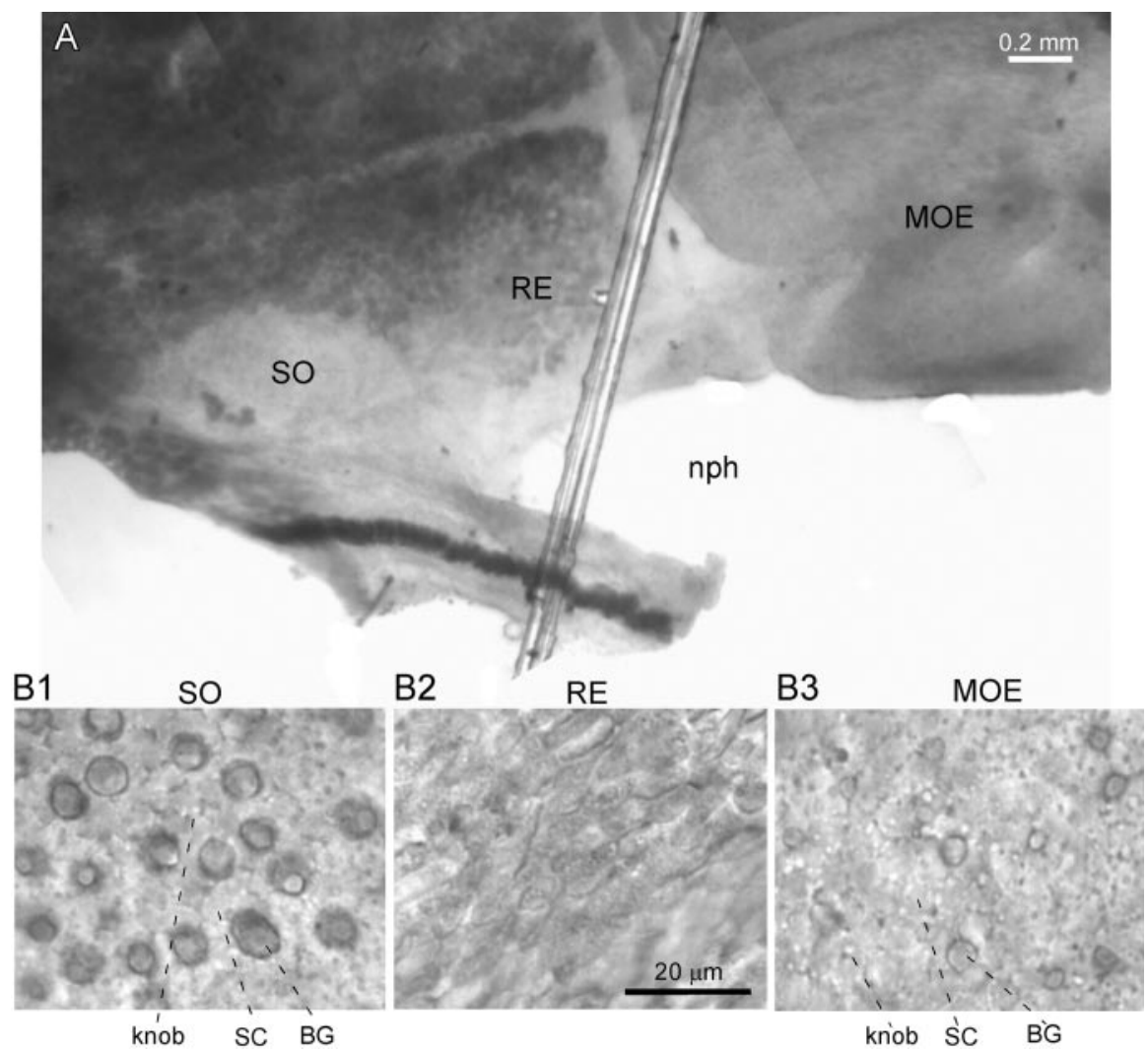

Figure 4. The septal organ as identified under DIC microscopy in living tissue. $A$, The ventral base of the intact epithelium on the septum viewed under DIC microscopy. The MOE and the $S O$ are separated from the RE by sharp boundaries. $B$, Both the $S O(B 1)$ and the $\mathrm{MOE}(B 3)$ are featured by evenly distributed Bowman's gland openings ( $B G$ ), supporting cells ( $S C$ ), and dendritic knobs of OSNs, whereas the RE (B2) is featured by epithelial cells with moving microvilli. $n p h$, Nasopharynx.

body, a specific marker for the GC-D neurons (Fig. 7). The PDE2-positive cells were scattered in the MOE with the highest density in the dorsal recess (Fig. 7A). The labeled cells (arrows) appeared bigger than the nonlabeled dendritic knobs (open arrowheads), because the labeling was in both the dendritic knobs and the cell bodies (Juilfs et a., 1997). The Bowman's gland openings ( filled arrowheads) throughout the epithelium appeared a little darker than the rest of the tissue, presumably attributable to the less efficient washing within these glands. The septal organ contained only a small subset of PDE2-positive cells, with an average \pm SD of $2.7 \pm 1.4(n=6)$ (Fig. $7 B)$.

The projection pattern of the mouse septal organ to the olfactory bulb was determined by DiI tracing (Fig. 8). The OSNs in the septal organ formed only one or two fascicles passing through the cribriform plate (Fig. $8 A$ ) and projected to $\sim 15$ glomeruli $(n=3$, 12,14 , and 19 from each animal, respectively) in the ventromedial aspect of the posterior bulb (Fig. $8 \mathrm{~B}$ ). These glomeruli almost formed a string along the anteroposterior axis (Fig. $8 B$ ). In most coronal sections, a single labeled glomerulus was observed (Fig. $8 C-E)$. Such a projection pattern is consistent with the fact that the septal organ did not contain a significant number of GC-DPDE2 cells (Fig. 7), which project to the necklace glomeruli forming a ring around the posterior bulb.

Among the labeled glomeruli, nearly half of them were densely labeled (Fig. 8C), and the rest were lightly labeled with incomplete arborization. Similar results have been reported on the projection pattern from the rat septal organ using HRP anterograde tracing (Giannetti et al., 1992). Presumably, the densely labeled glomeruli receive inputs mainly from the septal organ, whereas the lightly labeled ones are shared by sensory neuron axons from both the septal organ and the MOE (Giannetti et al., 1992). It should be noted that not every cell was labeled by DiI in our tracing experiments, which may lead to underestimation of the number of glomeruli the septal organ innervates. However, it is a reasonable assumption that the labeled glomeruli are the major targets converging inputs from a significant number of sensory neurons in the septal organ. In summary, these data indicate the septal organ resembles the main olfactory system in projecting to the main olfactory bulb.

\section{Discussion}

The current study provides the first comprehensive study on the functional properties of the OSNs in the septal organ, a littleexplored organ since its first identification 60 years ago. Our results revealed that the cAMP signaling is the major olfactory signal transduction mechanism in the septal organ. In addition, there is a small subset of cells that belongs to the GC-D-PDE2 subfamily. The OSNs in the septal organ resemble those in the MOE in their physiological properties and projection to the main olfactory bulb. Because the septal organ presents a much smaller system, functional and molecular characterization of the OSNs in this area will lead to a better understanding of olfactory coding mechanisms in general and shed light on its behavioral function.

\section{Signal transduction pathways in the septal organ}

A great deal of what we know about the organization and function of any sensory system has come from studies on the signal transduction mechanisms. By combining immunohistochemical and electrophysiological approaches, we evaluated the critical role played by the cAMP pathway in the septal organ.

The majority of OSNs in the septal organ were labeled with $\mathrm{G}_{\text {olf }}$ and ACIII, two key components in the cAMP pathway (Figs. 1,2 ), whereas only a few cells labeled with PDE2, a specific marker for the GC-D subfamily (Fig. 7) (Juilfs et al., 1997). The immunostaining patterns suggest that the cAMP pathway may play a critical role in signal transduction in the septal organ.

This is further supported by patch-clamp recordings from individual OSNs. Previous electroolfactogram recordings showed that the septal organ responds to a variety of odorants (Marshall and Maruniak, 1986). However, recording from individual OSNs in the septal organ was not practical before we developed the intact epithelial preparation in which single dendritic knobs could be visualized (Fig. 4). Similar to the main olfactory system, the OSNs in the septal organ responded to odorants by showing inward currents under voltage-clamp mode (Fig. 5A1). Such responses were mimicked by an adenylyl cyclase activator (Fig. 5B1, forskolin), a phosphodiesterase inhibitor (Fig. 5C1, $I B M X$ ), and a CNG channel activator (Fig. 5D1, 8-Br-cGMP). An adenylyl cyclase inhibitor (MDL12330A) blocked all of the responses except the one induced by 8 -Br-cGMP (Fig. $5 E$ ). These 


\section{Control}
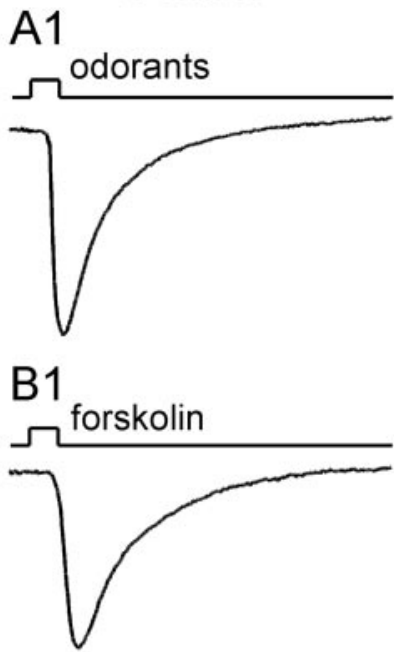

C1

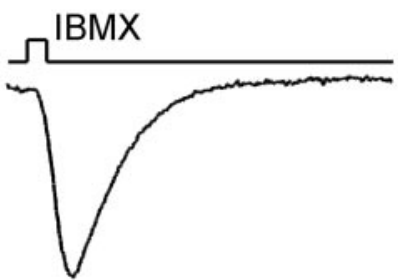

D1

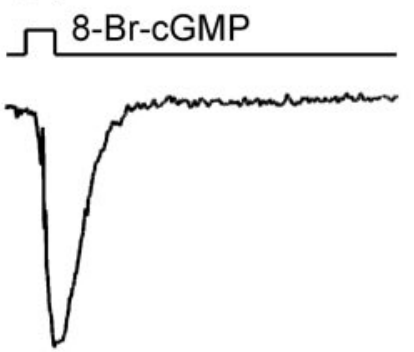

E

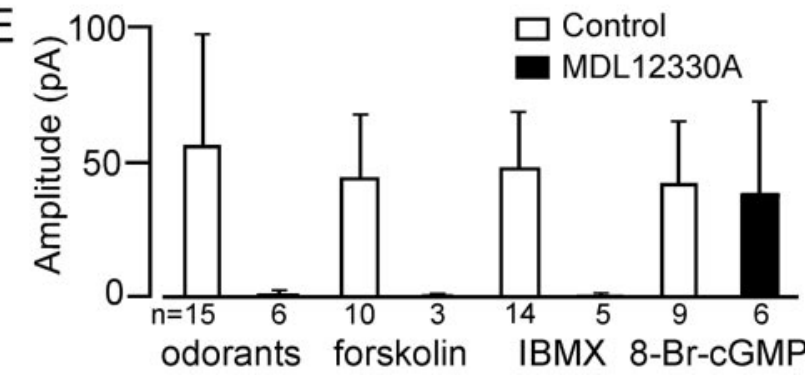

Figure 5. The cAMP pathway mediates olfactory signal transduction in the septal organ. Inward currents were induced under voltage-clamp mode by different stimuli: $A 1$, the odorant mixture at $100 \mu \mathrm{m} ; B 1,10 \mu \mathrm{m}$ forskolin, an adenylyl cyclase activator; $C 1,300 \mu \mathrm{m} \mathrm{IBMX}$, a phosphodiesterase inhibitor; and D1, $500 \mu \mathrm{m}$ 8-Br-CGMP, an activator of the CNG channel. The effects of $50 \mu \mathrm{M} M D L 12330 \mathrm{~A}$, an adenylyl cyclase blocker on the responses induced by the following: $A 2$, the odorant mixture at $100 \mu \mathrm{m} ; B 2,10 \mu \mathrm{m}$ forskolin; $C 2,300 \mu \mathrm{m} \mathrm{IBMX}$; and D2, $500 \mu \mathrm{m} 8$-Br-cGMP. Recordings in the same row were from the same cell. The holding potentials were $-50 \mathrm{mV}$ for all recordings. E, Summary of responses under different conditions. Data are expressed as means $\pm S D$ and pooled from $n$ cells, indicated as a number under each bar. The averaged responses induced by odorants, forskolin, and IBMX with MDL12330A are significantly smaller than those under control condition $(p<0.001)$. The averaged responses induced by $8-\mathrm{Br}-\mathrm{CGMP}$ are similar with or without MDL12330A $(p>0.4)$.
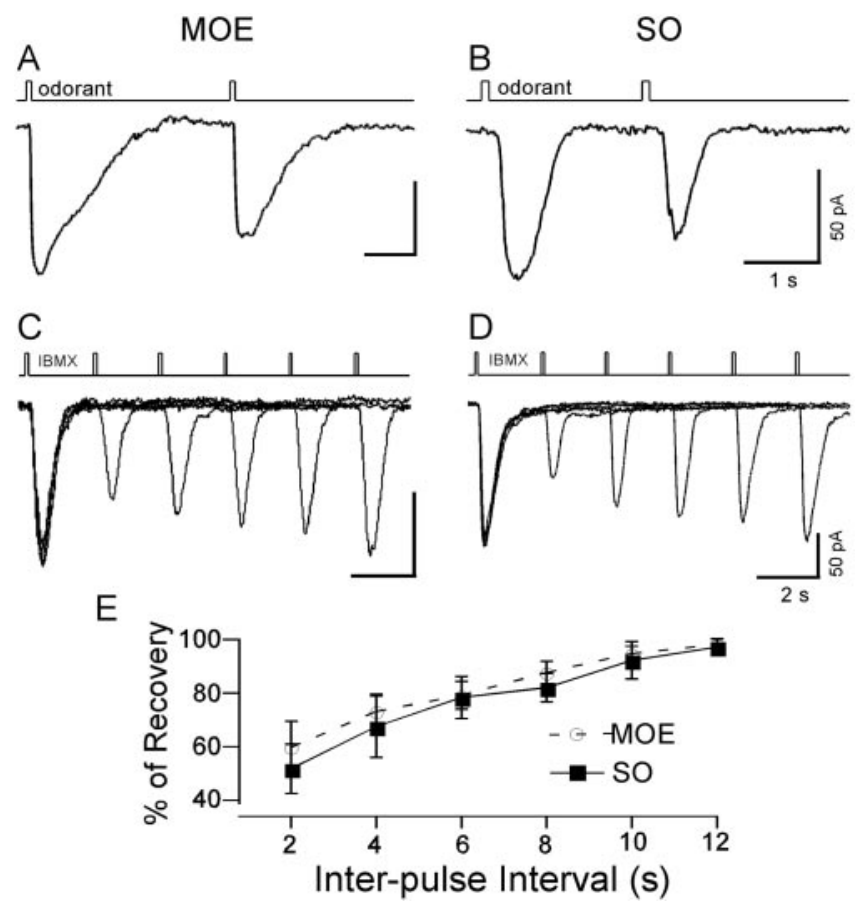

Figure 6. OSNs in the MOE and the septal organ show similar adaptation. Olfactory adaptation was induced by paired odorant pulses in individual OSNs in the MOE and in the septal organ. The odorant stimulus was cineole in $A$ and $(-)$ limonene in $B$ at $300 \mu \mathrm{m}$. OSNs from the MOE and the septal organ showed a similar time course in recovery from adaptation. $C, D, O S N$ s were stimulated by paired IBMX pulses ( $300 \mu \mathrm{m}, 100 \mathrm{msec}$ ) with increased interpulse intervals. The holding potentials were $-50 \mathrm{mV}$ for all recordings. E, Summary of the recovery fraction of the second IBMX responses versus the interpulse intervals. The response induced by a second pulse was normalized to the response induced by its preceding pulse. Data for MOE were averaged from eight cells, and data for the septal organ were averaged from six cells.
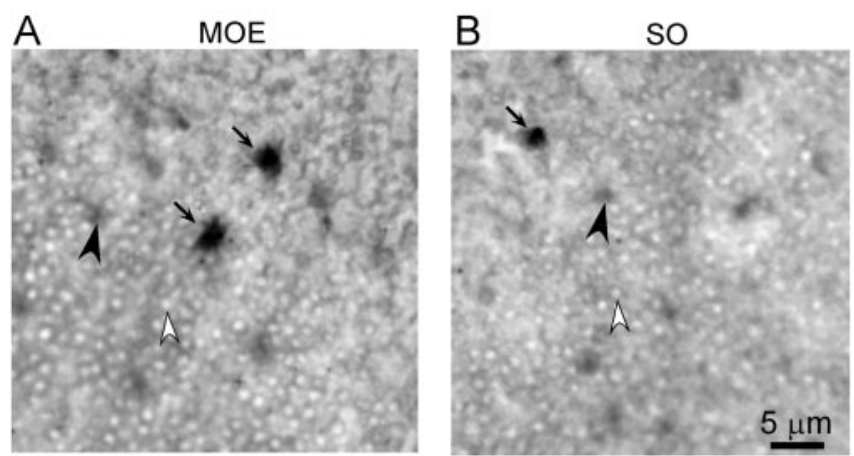

Figure 7. Only a few cells in the septal organ belong to the GC-D-PDE2 subfamily. Wholemount olfactory epithelium on the septum was reacted with PDE2 antibody. A, PDE-2-positive cells scattering in the MOE on the septum. B, A PDE-2-positive cell in the septal organ. Arrows mark the labeled OSNs. Filled arrowheads mark Bowman's gland openings. Open arrowheads mark dendritic knobs of OSNs.

data indicate that CAMP is the major second messenger mediating signal transduction in the septal organ, as well as in the MOE (Chen et al., 2000).

The septal organ, an attractive model for olfactory coding and processing studies

Functional studies of olfactory coding in mammals have been hindered by the inherent complexity of the system. There are millions of sensory neurons, each of which expresses one of $\sim 1000$ odorant receptors and responds to a broad range of odor- 

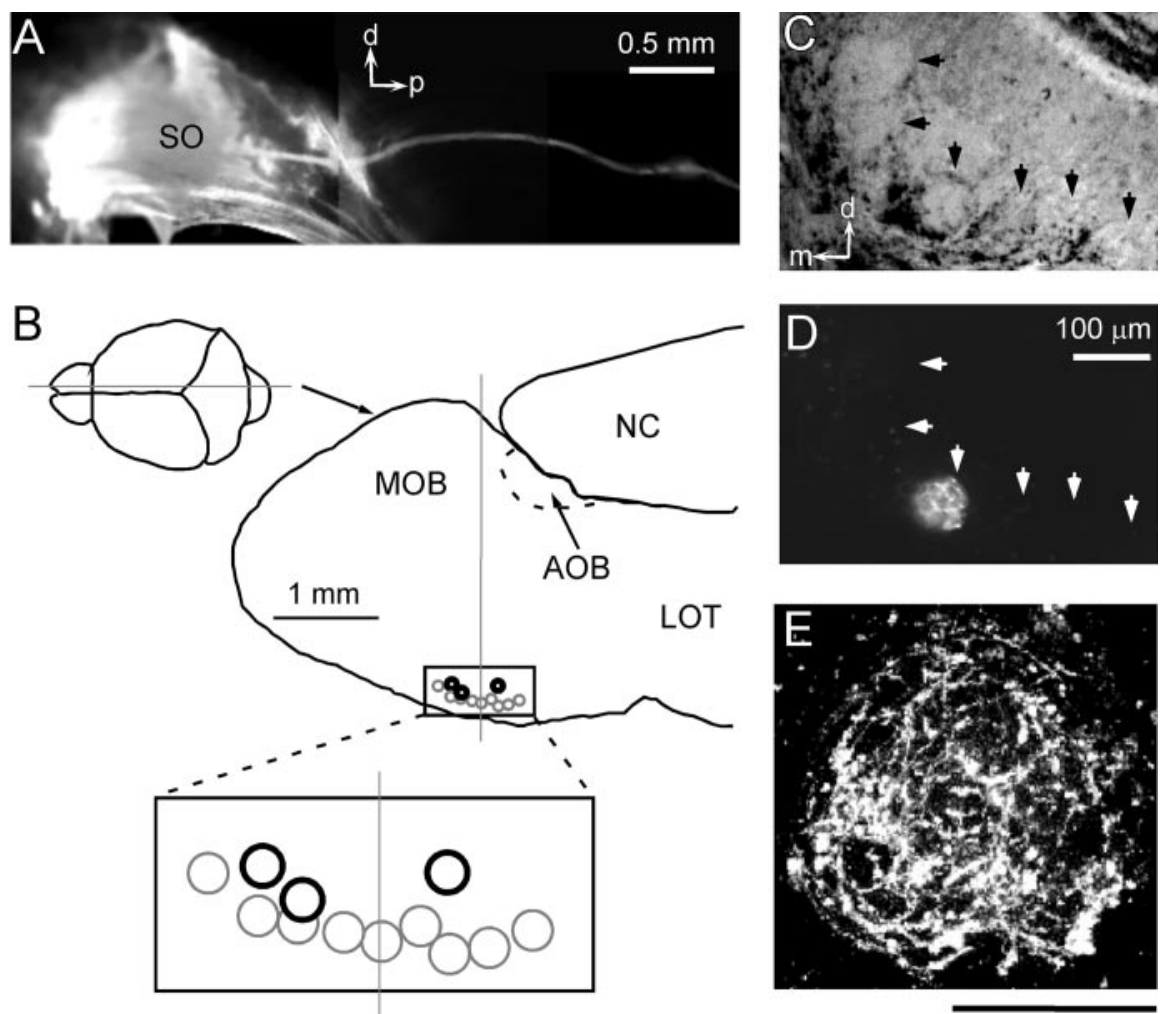

Figure 8. OSNs in the septal organ project to a subset of glomeruli in the MOB. A, The axons of OSNs in the septal organ often form only one or two fascicles that pass through the cribriform plate. Dil crystals were put on the septal organ, and the nasal septum was viewed under fluorescence illumination after 6 weeks. $d$, Dorsal; $p$, posterior. $B, 0 S N s$ in the septal organ project to a subset of glomeruli in the medial, ventral part of the posterior bulb. Darker circles indicate more lateral locations. $A O B$, Accessory olfactory bulb; LOT, lateral olfactory tract; $N C$, neocortex. C, D, A coronal section (indicated in $B$ ) viewed under infrared DIC microscopy (C) and fluorescence illumination (D). Arrows mark individual glomeruli. $m$, Medial; $d$, dorsal. $E$, The labeled glomerulus in $D$ viewed under higher magnification. Scale bar, $50 \mathrm{~mm}$.

ants from a pool of thousands (Mombaerts, 1999; Mori et al., 1999; Young et al., 2002; Zhang and Firestein, 2002). Limited knowledge is available on the odor response spectra of individual sensory neurons expressing a particular receptor gene, the overlap in response spectra between sensory neurons expressing different receptor genes, and the spatial distribution of OSNs with distinct response spectra. We hypothesize that the septal organ can serve as a smaller, potentially simpler model system to address these questions, because it constitutes $\sim 1 \%$ of the olfactory system and expresses a small fraction of the olfactory receptor genes (see below).

The septal organ resembles the MOE in many aspects. They have similar cellular compositions, such as olfactory sensory neurons, supporting cells, and Bowman's glands (Figs. 2, 4) (Graziadei, 1977; Kratzing, 1984; Miragall et al., 1984; Breipohl et al., 1989; Adams, 1992; Taniguchi et al., 1993; Giannetti et al., 1995a). In addition, the OSNs in both systems show similar odorant responses (Figs. 5, 6), which are mainly mediated by the cAMP pathway (Figs. 1, 2, 5). Furthermore, the septal organ projects to the main olfactory bulb, too (Fig. 8) (Pedersen and Benson, 1986; Astic and Saucier, 1988; Giannetti et al., 1992).

However, the septal organ presents a much smaller system than the main olfactory system. The MOE contains $\sim 2$ million OSNs, expresses $\sim 1000$ olfactory receptor genes, and projects to $\sim 2000$ glomeruli in the olfactory bulb. The mouse septal organ contains $<1 \%$ of the sensory neurons than the MOE, expresses a small fraction $(\sim 4 \%)$ of the olfactory receptor genes from a repertoire of $\sim 1000$ (our unpublished data), and projects to $\sim 1 \%$ of the glomeruli in the olfactory bulb (Fig. $8)$. With a manageable number of cells and receptor genes in a spatially defined area, olfactory coding studies in the septal organ will be greatly facilitated. It becomes possible and practical to obtain a complete picture of peripheral coding strategies addressing the questions mentioned above in the septal organ.

\section{Functional significance of the septal organ}

By virtue of its location, many authors have suggested that the septal organ may serve an alerting function by sensing odors in the environment during quiet respiration, when the air stream does not reach the MOE. This notion is supported by the fact that the septal organ can respond to some odorants with a higher sensitivity than the MOE (Marshall and Maruniak, 1986), but it is not proven by a lesional and behavioral study (Giannetti et al., 1995b). Another possibility has been suggested by Wysocki et al. (1980) that the septal organ may play a role in sensing compounds of low volatility, which can reach both the vomeronasal organ and the septal organ but not the MOE.

Our results showed that the majority of the sensory neurons in the septal organ and the MOE do not differ in their transduction machinery as far as they have been tested. This suggests that the special properties and function of the septal organ may result from its position within the nasal cavity, the specific olfactory receptor genes it expresses, and/or the specific projection pattern to higher brain centers. These possibilities require additional investigation. Our observation that the septal organ sensory neurons have flattened somata, shortened dendrites, and especially larger knobs is potentially interesting. This is in fact one of the rare differences described among the otherwise uniform morphology of sensory neurons in the MOE. Additional investigation of the response spectra of individual cells in the septal organ in a systematic way, combined with molecular studies, will expand our knowledge about olfactory coding in general and provide physiological clues to the function of this enigmatic organ.

\section{References}

Adams DR (1992) Fine structure of the vomeronasal and septal olfactory epithelia and of glandular structures. Microsc Res Tech 23:86-97.

Adams DR, McFarland LZ (1971) Septal olfactory organ in Peromyscus. Comp Biochem Physiol A 40:971-974

Astic L, Saucier D (1988) Topographical projection of the septal organ to the main olfactory bulb in rats: ontogenetic study. Brain Res 470:297-303.

Bakalyar HA, Reed RR (1990) Identification of a specialized adenylyl cyclase that may mediate odorant detection. Science 250:1403-1406.

Baker H, Cummings DM, Munger SD, Margolis JW, Franzen L, Reed RR, Margolis FL (1999) Targeted deletion of a cyclic nucleotide-gated channel subunit (OCNC1): biochemical and morphological consequences in adult mice. J Neurosci 19:9313-9321.

Belluscio L, Gold GH, Nemes A, Axel R (1998) Mice deficient in G(olf) are anosmic. Neuron 20:69-81.

Berghard A, Buck LB, Liman ER (1996) Evidence for distinct signaling 
mechanisms in two mammalian olfactory sense organs. Proc Natl Acad Sci USA 93:2365-2369.

Bojsen-Moller F (1975) Demonstration of terminalis, olfactory, trigeminal and perivascular nerves in the rat nasal septum. J Comp Neurol 159:245-256.

Bradley J, Reuter D, Frings S (2001) Facilitation of calmodulin-mediated odor adaptation by cAMP-gated channel subunits. Science 294:2176-2178.

Breer H, Boekhoff I, Tareilus E (1990) Rapid kinetics of second messenger formation in olfactory transduction. Nature 345:65-68.

Breipohl W, Naguro T, Miragall F (1983) Morphology of the Masera organ in NMRI mice (combined morphometric, freeze-fracture, light- and scanning electron microscopic investigations). Verh Anat Ges 77:741-743.

Breipohl W, Naguro T, Walker DG (1989) The postnatal development of Maresa's organ in the rat. Chem Senses 14:649-662.

Brunet LJ, Gold GH, Ngai J (1996) General anosmia caused by a targeted disruption of the mouse olfactory cyclic nucleotide-gated cation channel. Neuron 17:681-693.

Chen S, Lane AP, Bock R, Leinders-Zufall T, Zufall F (2000) Blocking adenylyl cyclase inhibits olfactory generator currents induced by "IP(3)odors". J Neurophysiol 84:575-580.

Firestein S, Darrow B, Shepherd GM (1991a) Activation of the sensory current in salamander olfactory receptor neurons depends on a $G$ proteinmediated cAMP second messenger system. Neuron 6:825-835.

Firestein S, Zufall F, Shepherd GM (1991b) Single odor-sensitive channels in olfactory receptor neurons are also gated by cyclic nucleotides. J Neurosci 11:3565-3572.

Fulle HJ, Vassar R, Foster DC, Yang RB, Axel R, Garbers DL (1995) A receptor guanylyl cyclase expressed specifically in olfactory sensory neurons. Proc Natl Acad Sci USA 92:3571-3575.

Giannetti N, Saucier D, Astic L (1992) Organization of the septal organ projection to the main olfactory bulb in adult and newborn rats. J Comp Neurol 323:288-298.

Giannetti N, Pellier V, Oestreicher AB, Astic L (1995a) Immunocytochemical study of the differentiation process of the septal organ of Masera in developing rats. Brain Res Dev Brain Res 84:287-293.

Giannetti N, Saucier D, Astic L (1995b) Analysis of the possible altering function of the septal organ in rats: a lesional and behavioral study. Physiol Behav 58:837-845.

Graziadei PPC (1977) Functional anatomy of the mammalian chemoreceptor system. In: Chemical signals in vertebrates (Muller-Schwarze D, Mozell MM, eds.), pp 435-454. New York: Plenum.

Greer CA, Stewart WB, Teicher MH, Shepherd GM (1982) Functional development of the olfactory bulb and a unique glomerular complex in the neonatal rat. J Neurosci 2:1744-1759.

Jones DT, Reed RR (1989) Golf: an olfactory neuron specific-G protein involved in odorant signal transduction. Science 244:790-795.

Juilfs DM, Fulle HJ, Zhao AZ, Houslay MD, Garbers DL, Beavo JA (1997) A subset of olfactory neurons that selectively express cGMP-stimulated phosphodiesterase (PDE2) and guanylyl cyclase-D define a unique olfactory signal transduction pathway. Proc Natl Acad Sci USA 94:3388-3395.

Katz S, Merzel J (1977) Distribution of epithelia and glands of the nasal septum mucosa in the rat. Acta Anat (Basel) 99:58-66.

Keller A, Margolis FL (1975) Immunological studies of the rat olfactory marker protein. J Neurochem 24:1101-1106.

Kramer RH, Siegelbaum SA (1992) Intracellular $\mathrm{Ca}^{2+}$ regulates the sensitivity of cyclic nucleotide-gated channels in olfactory receptor neurons. Neuron 9:897-906.

Kratzing JE (1984) The structure and distribution of nasal glands in four marsupial species. J Anat 139:553-564.

Kurahashi T (1990) The response induced by intracellular cyclic AMP in isolated olfactory receptor cells of the newt. J Physiol (Lond) 430:355-371.

Kurahashi T, Menini A (1997) Mechanism of odorant adaptation in the olfactory receptor cell. Nature 385:725-729.

Leinders-Zufall T, Shepherd GM, Zufall F (1995) Regulation of cyclic nucleotide-gated channels and membrane excitability in olfactory receptor cells by carbon monoxide. J Neurophysiol 74:1498-1508.

Lowe G, Gold GH (1993) Nonlinear amplification by calcium-dependent chloride channels in olfactory receptor cells. Nature 366:283-286.

Ma M, Shepherd GM (2000) Functional mosaic organization of mouse olfactory receptor neurons. Proc Natl Acad Sci USA 97:12869-12874.

Ma M, Chen WR, Shepherd GM (1999) Electrophysiological characterization of rat and mouse olfactory receptor neurons from an intact epithelial preparation. J Neurosci Methods 92:31-40.
Marshall DA, Maruniak JA (1986) Masera's organ responds to odorants. Brain Res 366:329-332.

Meyer MR, Angele A, Kremmer E, Kaupp UB, Muller F (2000) A cGMPsignaling pathway in a subset of olfactory sensory neurons. Proc Natl Acad Sci USA 97:10595-10600.

Miragall F, Breipohl W, Naguro T, Voss-Wermbter G (1984) Freezefracture study of the plasma membranes of the septal olfactory organ of Masera. J Neurocytol 13:111-125.

Mombaerts P (1999) Seven-transmembrane proteins as odorant and chemosensory receptors. Science 286:707-711.

Mori K, Nagao H, Yoshihara Y (1999) The olfactory bulb: coding and processing of odor molecule information. Science 286:711-715.

Munger SD, Lane AP, Zhong H, Leinders-Zufall T, Yau KW, Zufall F, Reed RR (2001) Central role of the CNGA4 channel subunit in $\mathrm{Ca}^{2+}$. calmodulin-dependent odor adaptation. Science 294:2172-2175.

Nakamura T, Gold GH (1987) A cyclic nucleotide-gated conductance in olfactory receptor cilia. Nature 325:442-444.

Pace U, Hanski E, Salomon Y, Lancet D (1985) Odorant-sensitive adenylate cyclase may mediate olfactory reception. Nature 316:255-258.

Pedersen PE, Benson TE (1986) Projection of septal organ receptor neurons to the main olfactory bulb in rats. J Comp Neurol 252:555-562.

Ring G, Mezza RC, Schwob JE (1997) Immunohistochemical identification of discrete subsets of rat olfactory neurons and the glomeruli that they innervate. J Comp Neurol 388:415-434.

Rodolfo-Masera T (1943) Su l'esistenza di un particolare organo olfacttivo nel setto nasale della cavia e di altri roditori. Arch Ital Anat Embryol 48:157-212.

Shinoda K, Shiotani Y, Osawa Y (1989) "Necklace olfactory glomeruli" form unique components of the rat primary olfactory system. J Comp Neurol 284:362-373.

Sklar PB, Anholt RR, Snyder SH (1986) The odorant-sensitive adenylate cyclase of olfactory receptor cells. Differential stimulation by distinct classes of odorants. J Biol Chem 261:15538-15543.

Spehr M, Wetzel CH, Hatt H, Ache BW (2002) 3-phosphoinositides modulate cyclic nucleotide signaling in olfactory receptor neurons. Neuron 33:731-739.

Taniguchi K, Arai T, Ogawa K (1993) Fine structure of the septal olfactory organ of Masera and its associated gland in the golden hamster. J Vet Med Sci 55:107-116.

Teicher MH, Stewart WB, Kauer JS, Shepherd GM (1980) Suckling pheromone stimulation of a modified glomerular region in the developing rat olfactory bulb revealed by the 2-deoxyglucose method. Brain Res 194:530-535.

Weruaga E, Brinon JG, Porteros A, Arevalo R, Aijon J, Alonso JR (2001) A sexually dimorphic group of atypical glomeruli in the mouse olfactory bulb. Chem Senses 26:7-15.

Wong ST, Trinh K, Hacker B, Chan GC, Lowe G, Gaggar A, Xia Z, Gold GH, Storm DR (2000) Disruption of the type III adenylyl cyclase gene leads to peripheral and behavioral anosmia in transgenic mice. Neuron 27:487-497.

Wysocki CJ, Wellington JL, Beauchamp GK (1980) Access of urinary nonvolatiles to the mammalian vomeronasal organ. Science 207:781-783.

Yagi T, Aizawa S, Tokunaga T, Shigetani Y, Takeda N, Ikawa Y (1993) A role for Fyn tyrosine kinase in the suckling behaviour of neonatal mice. Nature 366:742-745.

Young JM, Friedman C, Williams EM, Ross JA, Tonnes-Priddy L, Trask BJ (2002) Different evolutionary processes shaped the mouse and human olfactory receptor gene families. Hum Mol Genet 11:535-546.

Zhang X, Firestein S (2002) The olfactory receptor gene superfamily of the mouse. Nat Neurosci 5:124-133.

Zheng LM, Ravel N, Jourdan F (1987) Topography of centrifugal acetylcholinesterase-positive fibres in the olfactory bulb of the rat: evidence for original projections in atypical glomeruli. Neuroscience 23:1083-1093.

Zufall F, Leinders-Zufall T (2000) The cellular and molecular basis of odor adaptation. Chem Senses 25:473-481.

Zufall F, Munger SD (2001) From odor and pheromone transduction to the organization of the sense of smell. Trends Neurosci 24:191-193.

Zufall F, Firestein S, Shepherd GM (1991) Analysis of single cyclic nucleotide-gated channels in olfactory receptor cells. J Neurosci 11:3573-3580. 